\title{
TÉCNICAS DE REPRODUCCIÓN ASISTIDA LEGISLACIÓN ESPAÑOLA E ITALIANA
}

\author{
Francisca Jünemann
}

En este trabajo se analizan comparativamente las leyes española e italiana de reproducción asistida. El estudio se centra en los motivos de las leyes, los objetos de las mismas y, principalmente, el trato dado al embrión. La autora sugiere conclusiones sobre el modelo adecuado para legislar sobre la materia en Chile, teniendo en cuenta que el ordenamiento jurídico existente, a su juicio, protege a la persona desde la concepción.

Palabras clave: Reproducción asistida; leyes españolas de técnicas de reproducción asistida; ley italiana de técnicas de reproducción asistida; embrión humano.

Recibido: enero de 2008. Aceptado: noviembre de 2008.

\section{$\mathrm{L}$ 1. Introducción \\ os problemas de infertilidad y esterilidad en los seres humanos han llevado a la ciencia a desarrollar prácticas y procedimientos que facili- tan la fecundación de un óvulo con un gameto masculino y el inicio de un embarazo. Éstas son las llamadas técnicas de reproducción asistida, tales como la inseminación artificial, la fecundación in vitro e inyección intracito- plasmática de espermatozoides y la transferencia intratubárica de gametos.}

Francisca JÜnEMAnN P. Abogada. Licenciada en Derecho, Universidad Católica de Chile. Magíster en Derecho Civil y Derecho de Familia, Universidad de Barcelona. 
Los primeros antecedentes se remontan a 1944, año en que se fecundó un óvulo humano en probeta, sin resultados reproductivos. Luego, en 1978 se logra el primer embarazo con la puesta en práctica de técnicas de reproducción asistida in vitro y transferencia de embriones al útero, y nace en Gran Bretaña la primera niña como resultado exitoso del proceso. Desde entonces la técnica ha continuado desarrollándose en numerosos países, muchos de los cuales la han recogido en leyes específicas.

Esta tendencia internacional a regular por medio de legislaciones especiales las técnicas de reproducción asistida obedece a la intención de fijar los límites de las prácticas, no con miras a entrabar la ejecución y desarrollo de las mismas, sino con el objetivo de establecer el marco de protección de ciertos bienes jurídicos. Así, por medio de estas normas se determina la admisibilidad de las técnicas — qué es permitido realizar—, los actos prohibidos — qué es lo que no se puede hacer-y las consecuencias respecto del embrión, progenitores, familia y sociedad.

Chile carece de ley en la materia. Son los centros de medicina reproductiva los que determinan las prácticas admisibles ${ }^{1}$. Sin embargo, hay normas que, no versando específicamente sobre las técnicas de reproducción, abordan el derecho a la vida del no nacido: la Constitución de la República, el Código Civil, el Pacto San José de Costa Rica y la Ley 20.120. El artículo 19.1 de la Constitución asegura a todas las personas el derecho a la vida y ordena

${ }^{1}$ El Consenso Latinoamericano en aspectos ético-legales relativos a las técnicas de reproducción asistida, adoptado por países miembros de la Red Latinoamericana de Reproducción Asistida (Red), fue firmado en el año 1995 por diferentes centros de medicina reproductiva chilenos. El acuerdo, por medio de medidas específicas, trata de evitar la crioconservación ilimitada de embriones:

- Todo programa de criopreservación debe ir ligado a un programa de donación o adopción de embriones que permita encontrar una madre para aquellos que no serán transferidos a sus progenitores.

- Una de las maneras de minimizar sus aspectos negativos es reducir la cantidad de embriones a crioconservar, acortando de esta manera el tiempo en que serán transferidos y evitar nuevas estimulaciones hormonales para recuperar ovocitos hasta no haber transferido todos los embriones congelados.

— En las formas de consentimiento deben quedar establecidas las condiciones de uso de los embriones criopreservados (crioconservados), el tiempo máximo de ello y de la transferencia y la imposibilidad de nuevas estimulaciones ováricas hasta la transferencia de todos los embriones crioconservados. El consenso no es obligatorio ni tiene fuerza de ley. Tampoco obliga a los legisladores, sólo pretende ser una referencia.

Los centros chilenos actualmente inscritos en la Red son: Centro de Diagnóstico Sanitario Alemán, Centro de Estudios Reproductivos (CER), Clínica Los Dominicos, Programa de Fertilización Asistida IDIMI, Unidad de Medicina Reproductiva Clínica Alemana, Unidad de Medicina Reproductiva Clínica Las Condes, Unidad de Medicina Reproductiva Clínica Las Nieves, Unidad de Medicina Reproductiva Clínica de Reñaca. 
a la ley proteger la vida del que está por nacer. La sentencia del Tribunal Constitucional de mayo del 2008 precisa esta norma y señala que el embrión desde la concepción es persona y, por lo mismo, sujeto de derecho ${ }^{2}$. Según el artículo 75 del Código Civil la ley protege la vida del que está por nacer y el juez debe tomar todas las providencias para cautelar la existencia del no nacido. El artículo 4 de la Convención Americana sobre Derechos Humanos o Pacto de San José de Costa Rica, ratificado por Chile en 1990, reconoce el derecho a la vida de toda persona y que él está protegido, en general, a partir del momento de la concepción. Finalmente la Ley 20.120, que regula la investigación científica en el ser humano, su genoma y prohíbe la clonación, señala en su artículo primero que ella "tiene por finalidad proteger la vida de los seres humanos, desde el momento de la concepción”.

De estas normas, y especialmente de la mencionada sentencia del Tribunal Constitucional, se desprende que el marco legal chileno protege la vida del embrión como persona desde la concepción. Ante la existencia de embriones crioconservados o sobrantes sin destino, es probable que nuestro país se vea en la necesidad de aprobar una ley específica de reproducción asistida, para lo cual sería conveniente comenzar a revisar legislaciones existentes en otros países.

Este trabajo tiene por finalidad contribuir en esa tarea examinando dos legislaciones extranjeras: la española y la italiana. El análisis comparativo de las leyes de reproducción asistida de España e Italia se centra en tres materias. La primera son los motivos de la ley. La segunda —relativa al objeto de la ley— son los propósitos de la misma, qué es lo que busca. La tercera se refiere al trato dado al embrión — desprotección o protección desde la concepción-, tema de gran relevancia porque si bien los dos anteriores son importantes como antecedentes para la formación de una ley, éste es el que permite concluir el modelo que resulta más coherente con el ordenamiento jurídico existente en Chile ${ }^{3}$.

\footnotetext{
${ }^{2}$ Sentencia del Tribunal Constitucional de fecha 18 de abril de 2008, Rol 740-07CDS, IV. "Protección constitucional de la vida en Chile": "En efecto, si al momento de la concepción surge un individuo que cuenta con toda la información genética necesaria para su desarrollo constituyéndose en un ser distinto y distinguible completamente de su padre y madre — como ha sido afirmado en estos autos-, es posible afirmar que estamos frente a una persona en cuanto a sujeto de derecho. La singularidad que posee el embrión, desde la concepción, permite observarlo ya como un ser único e irrepetible que se hace acreedor, desde ese mismo momento, a la protección del derecho y que no podría simplemente ser subsumido en otra entidad, ni menos manipulado, sin afectar la dignidad sustancial de la que ya goza en cuanto persona”.

${ }^{3} \mathrm{Al}$ respecto véanse, por ejemplo, los trabajos de Ugarte Godoy, José Joaquín: "Momento en que el Embrión Es Persona Humana”, pp. 307 ss., y Bascuñán Rodríguez, Antonio: "La cuestión de la titularidad”, en su artículo "La Píldora del Día Después ante la Jurisprudencia”, pp. 48 ss., ambos publicados en Estudios Públicos el año 2004.
} 


\section{Motivos de las leyes}

\section{2.a) España}

España ha promulgado desde 1988 a la fecha tres normas sobre técnicas de reproducción asistida: las leyes 35/1988, 45/2003 y 14/2006.

La primera de ellas, la Ley 35/1988, promulgada a raíz de los avances que presentaban estas prácticas, fue un intento por acomodar el derecho al progreso científico, en cuanto el "asincronismo entre la ciencia y el derecho origina un vacío jurídico respecto de problemas concretos, que debe solucionarse si no es a costa de dejar a los individuos y a la sociedad misma en situaciones determinadas de indefensión. Las nuevas técnicas de reproducción asistida han sido generadoras de tales vacíos, por sus repercusiones jurídicas de índole administrativa, civil o penal”4.

La ley reconocía en sus motivos la necesidad de facilitar el desarrollo de la investigación científica y tecnológica y el imperativo de que ella sólo estuviera sujeta a limitaciones basadas en criterios fundados y razonables que evitaran la colisión con los derechos humanos y la dignidad de los individuos. La ciencia debía, a juicio de la ley, actuar respetando los derechos y libertades fundamentales de los hombres, de manera que, en estricto beneficio del ser humano, "no siempre va a ser posible ni debe hacerse lo que se puede hacer"5.

En los fundamentos de la Ley 35/1988 se reconocen distintas etapas de desarrollo del embrión: "se acepta que [las] distintas fases [del desarrollo embrionario] son embriológicamente diferenciables, con lo que su valoración desde la ética y su protección jurídica también deberían serlo”6.

Siguiendo estas directrices, la Ley 35/1988 consagró el carácter subsidiario de las técnicas y le dio al embrión cierto grado de protección, de acuerdo con su desarrollo, en las normas relativas a la admisibilidad de las técnicas y a los actos prohibidos. En cuanto a la admisibilidad, era requisito indispensable la esterilidad humana para facilitar la procreación en caso de no existir terapias alternativas (art. 1.2). Además, sólo se autorizaba la fecundación de óvulos humanos con fines de procreación (art. 3). Respecto a los actos prohibidos, no se aceptaba la investigación y experimentación con embriones in vitro viables, si no sólo cuando tuvieran carácter de diagnóstico y fines terapéuticos, y no más allá del día catorce después de la fecundación (art. 15). A su vez, toda intervención sobre el embrión vivo in vitro,

\footnotetext{
${ }^{4}$ Ley 35/1988, de 22 de noviembre sobre técnicas de reproducción asistida, motivos de la ley, parte II.

${ }^{5}$ Ley 35/1988, de 22 de noviembre sobre técnicas de reproducción asistida, motivos de la ley, parte I.

${ }^{6}$ Ley 35/1988, de 22 de noviembre sobre técnicas de reproducción asistida, motivos de la ley, parte II.
} 
con fines terapéuticos, no podía tener una finalidad distinta a la de tratar una enfermedad o impedir su transmisión (art. 13.1). Si los embriones no eran viables, se autorizaba investigar con otros fines (art. 15.3).

La Ley 35/1988 no limitó la cantidad de óvulos a fecundar por ciclo y permitió la crioconservación de embriones por un tiempo de cinco años, sin precisar el destino de ellos terminado el plazo. Los gametos o embriones crioconservados no procedentes de donantes debían quedar a disposición de los bancos correspondientes, después de dos años (art. 11). Las imprecisiones iniciales de la primera ley de reproducción asistida española provocaron un elevado número de embriones crioconservados sin destino ${ }^{7}$.

Como consecuencia de esta situación, la segunda ley española de reproducción asistida, la 45/2003, reformó los artículos 4 y 11 de la Ley 35/ 1988. Los objetos de la modificación fueron, en primer lugar, definir el destino de los embriones crioconservados sin destino y, en segundo, evitar la generación de nuevos embriones sobrantes en el futuro. Para darles destino a los embriones crioconservados, por medio de la modificación del artículo 11 se aumentó el tiempo de crioconservación de los embriones que ya estaban congelados, prolongándolo a todo el período de vida fértil de la mujer para su transferencia o donación a otra pareja o mujer infértil. En su defecto, se permitió donarlos a investigación o descongelarlos sin otro fin. Para evitar la generación de nuevos embriones sobrantes, se prohibió la crioconservación de embriones limitando a tres la cantidad de óvulos a fecundar y de embriones a transferir por ciclo reproductivo ${ }^{8}$. Excepcionalmente se autorizó la fecundación de más de tres óvulos y la crioconservación de los no transferidos para favorecer las posibilidades de embarazo ${ }^{9}$. De no ser transferidos a su madre, tendrían que ser donados a otra mujer infértil como única alternativa ${ }^{10}$.

${ }^{7}$ Se estimaba que en el año 2003 España tenía doscientos mil embriones congelados y de ellos, sesenta mil con más de cinco años (El País, 5 de julio de 2003, p. 30, España).

${ }^{8}$ Antes de iniciar un tratamiento se debía comprobar que la pareja, o la mujer en su caso, no tenía embriones crioconservados en algún centro nacional de reproducción asistida. De tenerlos, no le era posible iniciar un nuevo tratamiento hasta que todos ellos hubiesen sido transferidos (modificación del artículo 11 de la Ley 35/1988 por la Ley 45/2003).

${ }^{9}$ El Real Decreto 1720/2004, del 23 de julio, que establece las tipologías fisiopatológicas que permiten la superación de los límites generales establecidos para la fecundación de ovocitos en procesos de reproducción asistida”, permitió la fecundación excepcional de más de tres ovocitos en el mismo ciclo, por esterilidad de causa masculina (azoospermia y oligoastenoteratozoospermia) y femeninas (ciertas patologías ováricas como reserva folicular disminuida u ovarios poliquísticos, patología tuboperitonal, como endometriosis, esterilidad de origen desconocido, obesidad, pobres resultados en ciclos anteriores, casos con indicación para diagnóstico genético preimplantacional, ovocitos difícilmente reemplazables y donación de ovocitos).

${ }^{10}$ Para eso se debía firmar el "Compromiso de Responsabilidad sobre sus Embriones Crioconservados”, en el cual la pareja o mujer en su caso (usuaria sola sin pareja, en caso de donación de gametos) debía aprobar una cláusula que autorizaba —en el supuesto 
Estos intentos de la Ley 45/2003 por dar más protección al embrión, evitar su crioconservación y la existencia de embriones sin destino acabaron tres años después con la derogación de la Ley 35/1988 por la nueva Ley 14/2006 de técnicas de reproducción asistida, vigente hoy. Los importantes avances científicos constatados en los últimos años, el desarrollo de nuevas técnicas, el aumento del potencial investigador y la necesidad de definir el destino de los embriones sobrantes hicieron, a juicio del legislador español, necesaria la derogación de la Ley 35/1988. Éste consideró que la Ley 45/ 2003 sólo dio una respuesta parcial a las necesidades, especialmente por la limitación para investigar con los embriones congelados y el límite de tres ovocitos a fecundar por ciclo, "lo que dificultaba la práctica ordinaria de las técnicas de reproducción asistida, al impedir poner los medios para lograr el mayor éxito con el menor riesgo posible para la salud de la mujer”"11.

En atención a estos motivos, las normas de la actual ley consagran niveles diferentes de valoración del concebido según las etapas de desarrollo, así como permiten aplicar las técnicas para fines distintos al de procreación humana y, a su vez, eliminan la esterilidad o infertilidad como requisito de acceso a ellas.

\section{2.b) Italia}

Italia sólo ha promulgado una ley de técnicas de reproducción asistida, la 40/2004, que rige hasta hoy. Ésta no ha sufrido reforma alguna hasta la fecha, no obstante un intento por modificarla en el referéndum de junio del año $2005^{12}$.

que sus preembriones no le fueran transferidos en el plazo previsto- su donación con fines reproductivos como única alternativa. No podían ser destinados a investigación. Para garantizar el cuidado de los embriones por parte de los centros se creó un seguro para compensar económicamente a la pareja en caso de accidente o siniestro que afecte a los crioconservados. Todo lo anterior por modificación del artículo 11 de la Ley 35/1988 por la Ley 45/2003.

${ }^{11}$ Ley 14/2006, exposición de motivos. Incidieron en las nuevas normas las directrices vertidas por la Comisión Nacional de Reproducción Asistida, órgano colegiado de carácter permanente, dirigido a orientar y asesorar sobre la utilización de las técnicas y a contribuir a la actualización y difusión de los avances científicos. Fue creada por el Real Decreto 415/1997 de 21 de marzo y modificada por el Real Decreto 906/2007 de 6 de julio, para adaptarla a la nueva ley.

${ }^{12}$ La consulta se refería a la experimentación con embriones (con células estaminales y embriones crioconservados), la clonación con transferencia de núcleo, la crioconservación, la eliminación del límite máximo de tres óvulos a fecundar por ciclo, el diagnóstico preimplantacional, la fecundación heterogénea y la aplicación de las técnicas a personas que no sufran de esterilidad o infertilidad (como aquellas portadoras de enfermedades genéticas). Sin embargo, el referéndum fracasó al no lograr la votación necesaria del 50\% más uno. Sólo el 25,9\% de los italianos votó y la consulta fue declarada nula. 
Antes de la aprobación de la ley, las técnicas de reproducción asistida ya se realizaban en Italia, pero sólo estaban normadas en el sector público $^{13}$. Por medio de la Ley 40/2004 la regulación se extiende también a la esfera privada, quedando estas prácticas reglamentadas homogéneamente en todos los centros de medicina reproductiva del país. Al generalizar la regulación de las técnicas de reproducción asistida el legislador reconoce en el artículo primero de la Ley el derecho de las parejas estériles o infértiles de acceder a las técnicas, y reconoce al embrión como sujeto de derecho de la vida humana desde la concepción (con base en la sentencia del Tribunal Constitucional 35/199714).

De haberse tomado otra decisión "se habrían planteado razones de inconstitucionalidad en el caso de que la Ley 40/2004 hubiera realizado elecciones de fondo distintas (especialmente en relación con la posible cosificación de la vida humana en su fase precoz y la posible incidencia de las coincidencias genéticas sobre la titularidad de los derechos humanos)”"15.

Si bien el principal principio que determina las estipulaciones de la ley es el reconocimiento de los derechos de los sujetos involucrados — de las parejas con problemas de esterilidad o infertilidad y del embrión-, el carácter supletorio de las técnicas de reproducción asistida, la tutela de la familia y el derecho de los hijos a tener como padres a sus verdaderos progenitores son también bienes acogidos por la Ley 40/2004.

${ }^{13}$ El gobierno dictó una serie de ordenanzas en la materia desde 1985 hasta el año 2001. En 1985 el Ministerio de Salud emitió una circular relativa a los límites y condiciones de legitimidad de los servicios de inseminación artificial en el ámbito del Servicio Sanitario Nacional. Sus disposiciones eran aplicables en el sector público, no privado, quedando estos últimos en libertad de acción. Se exigía a los usuarios de las técnicas ser cónyuges no separados, con gametos propios; sólo se podía fecundar los óvulos que se iban a transferir de manera inmediata, y se prohibía la crioconservación de embriones para uso industrial, de investigación o de transferencia sucesiva. En 1997, el ministerio por medio de ordenanzas prohibió la comercialización y publicidad relativa a gametos y embriones humanos y la clonación humana o animal. El 25 de julio de 2001 otra ordenanza prohibió la importación y exportación de gametos y embriones humanos. (Casini, Carlos; Marina Casini y María Luisa Di Pietro: La legge 19 de febbraio 2004, $N^{\circ}$ 40, Norme en materia di procreazione medicalmente assistita, commentario, 2004.)

${ }^{14}$ El artículo 2 de la Constitución italiana señala: "La República reconoce y garantiza los derechos inviolables del hombre, ora como individuo, ora en el seno de las formaciones sociales donde desarrolla su personalidad, y exige el cumplimiento de los deberes inexcusables de solidaridad política, económica y social”. La sentencia del Tribunal Constitucional $N^{\circ}$ 35/1997 se remite a la Declaración universal de los derechos del niño que otorga a la "falta de madurez física e intelectual" un mayor derecho a la protección "tanto antes como después del nacimiento" (Eusebi, Luciano, "Problemas Jurídicos de la Fecundación Humana Extracorpórea: La Normativa Italiana”, 2006). La ley italiana de reproducción asistida respetó a su vez el Convenio Europeo sobre Derechos Humanos y Biomedicina (denominado de Oviedo) que impone a la ley la obligación de garantizar una adecuada protección al embrión.

${ }^{15}$ Eusebi, Luciano: "Problemas Jurídicos de la Fecundación Humana Extracorpórea: La Normativa Italiana”, 2006. 


\section{Objetos de las leyes}

3.a) España

Al analizar la Ley española 14/2006 de reproducción asistida es posible distinguir tres objetos, más allá de lo declarado en el artículo primero de la Ley ${ }^{16}$. El primero es obtener más éxito en la aplicación de las técnicas. El segundo, admitir las técnicas de reproducción asistida para fines ajenos a la reproducción humana. Y el tercero, consagrar la reproducción asistida como un derecho de toda persona.

Para lograr la primera finalidad — mayor éxito de las técnicas - permite fecundar óvulos por ciclo sin limitar la cantidad. Consecuencialmente, admite la crioconservación ilimitada de los embriones sobrantes.

Para el segundo propósito - hacer admisibles las técnicas de reproducción asistida para fines ajenos a la reproducción humana - no prohíbe fecundar óvulos humanos con fines distintos al de procreación, prohibición que sí contemplaba expresamente la derogada Ley 35/1988 ${ }^{17}$. Así, permite la investigación y experimentación con embriones y el diagnóstico genético preimplantacional tanto para enfermedades genéticas de los tratantes como para la cura de enfermedades de terceras personas. La ley, ya en la exposición de motivos, señala que las técnicas de reproducción asistida han tenido una evolución en su aplicación al extenderla a otros problemas como enfermedades $^{18}$. El art. 1 a) precisa que uno de los objetos de la ley es "regular la aplicación de las técnicas de reproducción humana asistida en la prevención y tratamiento de enfermedades de origen genético” y el art. 12.2, que se podrá realizar el diagnóstico genético preimplantacional para este u otros fines (Ley 14/2006).

La ausencia de una norma en la Ley 14/2006 que prohíba la fecundación de óvulos humanos con fines distintos a la procreación creó la duda de si la ley busca autorizar la generación de embriones directamente con fines de investigación y experimentación, a pesar de la prohibición del artículo 161 del Código Penal y del Convenio de Oviedo que prohíben la constitución de embriones humanos con dichos propósitos ${ }^{19}$. La imprecisión quedó

${ }^{16} \mathrm{El}$ art. 1.1 de la Ley 14/2006 señala que ésta tiene por objeto regular la aplicación de las técnicas de reproducción asistida debidamente acreditadas, regular la aplicación de las técnicas en la prevención y tratamiento de enfermedades de origen genético y regular los supuestos y requisitos de utilización de los gametos y preembriones humanos crioconservados.

${ }^{17}$ La Ley 35/1988 en su artículo 3 establecía como práctica prohibida la fecundación de óvulos humanos con fines distintos al de procreación.

${ }^{18}$ Exposición de motivos, parte II, Ley 14/2006.

${ }^{19}$ Artículo 18.2, Convenio Europeo sobre Derechos Humanos y Biomedicina (Oviedo), del 4 de abril de 1997, ratificado por España el 23 de julio de 1999. 
aclarada por la Ley 14/2007 de investigación biomédica, la cual prohíbe en el artículo 33 generar embriones con fines de experimentación o investigación. Los embriones que se destinen a ello, por lo tanto, serán los sobrantes de las técnicas de reproducción asistida.

Para alcanzar el tercer propósito — consagrar la reproducción asistida como un derecho de toda persona—- la ley no exige, en la aplicación de una técnica, causa de infertilidad o esterilidad humana ${ }^{20}$. Es aplicable en personas fértiles que pueden procrear naturalmente, como en aquellas portadoras de enfermedades genéticas y en mujeres solas ${ }^{21}$. Si bien ya la antigua ley autorizaba las prácticas heterólogas — donación de gametos o embriones por terceros_-, pudiendo en la práctica acceder a ellas una mujer sin pareja, la nueva Ley 14/2006 (art. 6.1) consagra expresamente que puede una mujer ser usuaria o receptora de una técnica “con independencia de su estado civil y orientación sexual”, teniendo como base el término del carácter supletorio del acto sexual como requisito de aplicación de una técnica de reproducción asistida. La única limitación de acceso a una técnica de reproducción asistida, por parte de una persona o pareja, estaría en la prohibición de maternidad subrogada o de sustitución, como se verá más adelante.

\section{3.b) Italia}

Antagónicamente, la Ley italiana 40/2004 tiene un solo objeto: facilitar la procreación humana cuando parejas heterosexuales no pueden lograrlo en forma espontánea. Para ello establece una serie de exigencias y prohibiciones.

La ley exige que el usuario sea una pareja estable con problemas de esterilidad o infertilidad, que haya certeza en la imposibilidad de remover de otra forma la causa que haga imposible procrear espontáneamente, que no existan otros métodos terapéuticos eficaces para remover la causa de esterilidad o infertilidad y que se tenga conocimiento cierto de ella (Ley 40/2004, art. 1.2, art. 4.1 y art. 5.1). Estas exigencias implícitamente están excluyendo de la posibilidad de acceder a una técnica a las parejas fértiles pero portadoras de enfermedades genéticas, con el fin de evitar la transmisión de esas enfermedades. Expresamente prohíbe las prácticas heterólogas y excluye a las parejas en que ambos sean del mismo sexo (art. 12.1 y art. 12.2).

${ }^{20} \mathrm{El}$ art. 1 de la Ley 35/1988 señalaba que las técnicas podían ser utilizadas en caso de esterilidad humana para facilitar la procreación de no existir otras terapias alternativas.

${ }^{21}$ La nueva Ley 14/2006 deroga las disposiciones del artículo primero de la antigua Ley 35/1988 que exigía esterilidad humana para facilitar la procreación en caso de no existir otras terapias alternativas. 
La Ley italiana 40/2004 prohíbe todas aquellas prácticas que de alguna forma desligan a la técnica de la reproducción humana, tales como la producción de embriones con fines de investigación, experimentación o para cualquier fin distinto al de procreación humana, y prohíbe la selección eugenésica de embriones y de gametos destinada a alterar el patrimonio genético (a excepción de aquellas intervenciones que tengan fines diagnóstico o terapéuticos) (art. 13.3, letras a y b, de la Ley 40/ 2004).

No obstante estas diferencias esenciales entre las legislaciones española e italiana, ambas coinciden en prohibir la maternidad subrogada o de sustitución ${ }^{22}$. Por tal se entiende que "una parte encarga a una mujer la gestación, alumbramiento y entrega del nacido al comitente o a un tercero, con o sin precio, renunciando a reclamar la determinación legal de su maternidad". Se trata, entonces, de un contrato por el cual se conviene la gestación, remunerada o no, a cargo de una mujer que renuncia a la filiación materna a favor de un contratante o tercero. Una de las partes puede ser una persona sola, pareja matrimonial o convivencial o un comitente que actúa para un tercero, que es la persona o pareja que pretende la relación de filiación respecto del fruto del encargo. La otra parte es siempre una mujer que se obliga a gestar (con material reproductor ajeno o propio), alumbrar y entregar al nacido ${ }^{23}$.

La ley española declara nulo este contrato debido a que la prestación del mismo — gestar a un hijo para entregarlo a otro— no es lícita "al no ser conforme con las leyes, las costumbres y los usos sociales” consagrados en el artículo 1271 inciso 3 y 1275 del Código Civil español. La persona no puede ser objeto de contrato 24 .

De producirse la subrogación de una maternidad no obstante la prohibición legal, la ley de reproducción asistida española señala que la filiación de los hijos nacidos por gestación de sustitución será determinada por el parto ${ }^{25}$. Así, la madre será la mujer que esperaba entregar al

${ }^{22}$ Art. 10, Ley 14/2006 de técnicas de reproducción asistida española, y art. 12.6, Ley 40/2004 de técnicas de reproducción asistida italiana.

${ }^{23}$ Ferrer, María Pilar: “Gestación por Sustitución: Comentario Jurídico”, 2007.

${ }^{24}$ Ferrer: ibídem. El Código Civil español señala: "Pueden ser igualmente objeto de contrato todos los servicios que no sean contrarios a las leyes o las buenas costumbres" (art. 1271 inciso 3); "Los contratos sin causa, o con causa ilícita, no producen efecto alguno. Es ilícita la causa cuando se opone a las leyes o la moral” (art. 1275).

25 "Será nulo de pleno derecho el contrato por el que se convenga la gestación, con o sin precio, a cargo de una mujer que renuncia a la filiación materna a favor de un contratante o un tercero. La filiación de los hijos nacidos por gestación de sustitución será determinada por el parto. Queda a salvo la posible acción de reclamación de la paternidad respecto del padre biológico, conforme a las reglas generales” (Ley 14/ 2006, art. 10). 
nacido y no la que deseaba recibirlo como hijo. En Italia, la maternidad también queda determinada por el parto, por lo que la situación es igual a la española.

\section{Trato al embrión en las leyes}

Las leyes española e italiana de reproducción asistida dan disímil valoración y protección al embrión. La primera desconoce cualquier garantía de desarrollo del mismo, mientras que todas las normas de la segunda se circunscriben a la permanente protección del embrión.

Las diferencias de ambas legislaciones se dan en diversas materias: valoración del embrión según nivel de desarrollo, investigación y experimentación con embriones, crioconservación de los mismos, diagnóstico genético preimplantacional de embriones, clonación y técnicas terapéuticas en él.

\section{4.a) Valoración del embrión según nivel de desarrollo}

La Ley 14/2006 de técnicas de reproducción asistida española reconoce diferentes niveles de valoración del óvulo fecundado según su etapa de desarrollo, considerándolo preembrión hasta el día catorce: “A los efectos de esta ley se entiende por preembrión el embrión in vitro constituido por el grupo de células resultantes de la división progresiva del ovocito desde que es fecundado hasta el día catorce más tarde”26.

El propósito es admitir la investigación y experimentación con embriones, la selección por diagnóstico preimplantacional y la clonación terapéutica en los primeros catorce días. Así, busca eludir el Convenio Europeo sobre los Derechos Humanos y Biomedicina (Oviedo, 4 de abril de 1997), que obliga en su artículo 18 a que toda experimentación con embriones garantice una adecuada protección del mismo, y de la Recomendación 1046 (1986) del Consejo de Europa, que no permite intervenciones sobre embriones vivos in vitro, salvo que sea para su bienestar y para facilitar su desarrollo y nacimiento.

${ }^{26}$ Ley 14/2006, art. 1 letra c) 2. El concepto de preembrión tiene como antecedente una sentencia del Tribunal Constitucional Alemán de 1975: "vida, en el sentido de existencia histórica de un individuo, existe en todo caso, de acuerdo con conocimientos científicos seguros, a partir del decimocuarto día después de la concepción” (Sentencia BverfGE 39,1, 37). Su argumento se basa en que en el día catorce se produce la anidación en caso de fecundación natural dentro del cuerpo de la madre y porque hasta ese día el embrión no tiene aún la línea primitiva u organogénesis, que determina la información genética y es posible la formación de gemelos monocigóticos, por lo que antes no existiría identidad individualizada. 
La ley italiana, por el contrario, valora al embrión desde el primer momento de la concepción, sin diferenciar etapas de desarrollo. Asegura en su artículo primero el derecho de todos los sujetos involucrados, incluido el concebido. Este reconocimiento lleva a la ley a prohibir cualquier práctica -de aquellas llamadas coadyuvantes de la reproducción asistida- que afecte el desarrollo del embrión, como la manipulación, la investigación y experimentación sobre el mismo, la selección de embriones por diagnóstico preimplantacional y la clonación. Esta decisión del legislador se fundamenta en el Convenio Europeo sobre los Derechos Humanos y Biomedicina (Oviedo, 4 de abril de 1997), que exige a toda experimentación con embriones garantizar su adecuada protección, y en la Declaración de Helsinki de la Asociación Médica Mundial, que llama a la investigación médica a proteger la vida, salud y dignidad del ser humano ${ }^{27}$.

\section{4.b) Investigaciones sobre el embrión}

Debido a las diferentes etapas de desarrollo que la ley española reconoce en el embrión y a la diversa valoración que les da, la investigación se admite sobre él —llamado “preembrión” en la ley_ hasta el día catorce cuando sea sano y viable ${ }^{28}$. Al no distinguir la viabilidad de un embrión como tampoco su estado de vivo o muerto, la ley equipara el trato al embrión hasta el día catorce con el dado a los gametos. Estos embriones —o preembriones según la Ley 14/2006 — deben ser sobrantes de las técnicas de reproducción asistida y no haberse creado especialmente con fines de investigación, en cuanto la Ley 14/2007 de investigación biomédica lo prohíbe.

${ }^{27}$ El artículo 18 del Convenio de Oviedo señala que si la experimentación con embriones está admitida por ley, ésta deberá garantizar una adecuada protección del embrión.

La Declaración de Helsinki de la Asociación Médica Mundial señala que en la investigación en seres humanos deben primar los intereses de los seres humanos antes que los de la ciencia y sociedad, y que la investigación médica debe proteger la vida, salud y dignidad del ser humano (puntos 6 y 7) (Ob. cit. nt. 20 pp. 74).

${ }^{28}$ El artículo 15.1 de la Ley 14/2006, que señala los requisitos de investigación sobre el preembrión, no menciona la exigencia de que sean preembriones que ya se encuentran crioconservados ni que sean preembriones no viables. Los únicos requisitos que exige son: el consentimiento expreso de la pareja, que no hayan estado in vitro más allá del día catorce y que la investigación se realice en base a proyectos presentados y autorizados.

El artículo 18.1 del Convenio de Oviedo sobre experimentación en el embrión señala: “Cuando la experimentación con embriones in vitro esté admitida por ley, ésta deberá garantizar una protección adecuada al embrión”, norma que no se cumple en España respecto de los embriones sobrantes, los cuales dejan de ser objeto de protección. 
La cantidad de embriones susceptibles de investigación es ilimitada, ya que la ley española no limita la cantidad de óvulos a fecundar ni, por consiguiente, el número de embriones sobrantes por ciclo. Si bien la ley castiga como infracción grave "la generación de un número de preembriones en cada ciclo reproductivo que supere el necesario, conforme con los criterios clínicos, para garantizar en límites razonables el éxito reproductivo en cada caso” (art. 26.2, b.8, Ley 14/2006), será inevitable la existencia de un sinnúmero de embriones sobrantes, tal como ocurrió con la primera ley española, la 35/1988 (antes de la reforma introducida por la Ley 45/2003), principalmente porque los embriones sobrantes se pueden destinar a fines distintos de la procreación humana.

Italia, en cambio, prohíbe en la Ley 40/2004 de reproducción asistida “cualquier experimentación sobre cualquier embrión humano” (art. 13.1). Esto, aunque no sean viables. La investigación clínica y experimental está permitida sólo en la medida en que persiga fines terapéuticos y diagnósticos en el embrión, siempre que tutele su salud y desarrollo y en caso de no existir metodologías alternativas (art. 13.1).

La decisión de la ley italiana de prohibir la investigación con embriones es consecuencia de la protección que les otorga desde el momento de la concepción. La investigación implica la muerte del embrión, elimina cualquier posibilidad de desarrollo posterior a ella y, por lo mismo, los beneficios buscados por los investigadores — como el conseguir cura a enfermedades humanas - no pueden estar sobre el derecho del sujeto protegido, que es el embrión.

\section{4.c) Crioconservación de embriones}

Consecuencia de la fecundación ilimitada de óvulos, la Ley 14/2006 de reproducción asistida española permite la crioconservación —congelación- de los embriones no transferidos a la mujer en un ciclo reproductivo, llamados embriones sobrantes. Al estar la ley orientada a lograr el mayor éxito en las tasas de embarazos y asegurar la salud de la mujer, la crioconservación se ve como la alternativa para tener un número de óvulos fecundados suficiente para lograr un embarazo y a la vez evitar que éste sea múltiple (de dos o más fetos). De esta forma, selecciona sólo los mejores embriones a transferir y congela los no transferidos, llamados sobrantes. A su vez, persigue evitar que la mujer se someta nuevamente al tratamiento de estimulación ovárica y extracción de óvulos. 
La crioconservación de embriones se realiza cuando se seleccionan los embriones a transferir, que es aproximadamente dentro de las primeras cuarenta y ocho horas de extraídos los óvulos y se puede prolongar hasta que lo consideren los responsables médicos, por lo que se podría extender más allá de la vida fértil de la mujer (art. 11.3, Ley 14/2006).

Los destinos posibles de los embriones crioconservados son la transferencia a la misma mujer, la donación con fines reproductivos a otra mujer o pareja, la donación con fines de investigación o el cese de su conservación sin otra utilización, cuando finalizado el tiempo máximo de conservación no se haya optado por las otras alternativas (Ley 14/2006, art. 11.4).

Por el contrario, en Italia se prohíbe la crioconservación de embriones, de manera expresa en el art. 14.1 de la Ley 40/2004 de reproducción asistida. Limita los óvulos a fecundar a los estrictamente necesarios para ese ciclo con un máximo de tres y obliga a transferir todos los fecundados, evitando la existencia de embriones sobrantes (art. 14.2). Esta decisión se fundamenta en la resolución sobre la fecundación in vitro aprobada en 1989 por el Parlamento Europeo, que obliga a producir sólo los embriones estrictamente necesarios para un ciclo de transferencia y es una medida que va en la dirección de garantizar la vida del embrión desde la concepción ${ }^{29}$.

No obstante estar la crioconservación prohibida en Italia, en la misma línea de garantizar el desarrollo del concebido, la ley italiana de reproducción asistida permite excepcionalmente crioconservar embriones cuando la transferencia al útero de la madre no sea posible por hechos de fuerza mayor e imprevisibles relacionados con el estado de salud de la mujer, y sólo hasta el momento en que cese el impedimento y sea posible la transferencia ${ }^{30}$. La ley no da una solución cuando la imposibilidad de transferencia a la madre es definitiva, sea por muerte o enfermedad sobreviviente incompatible con el embarazo. El legislador no dio la posibilidad excepcional de donar esos embriones a otra pareja con problemas reproductivos, consagrando la prohibición de las prácticas heterólogas de forma absoluta. Por lo

\footnotetext{
${ }^{29}$ Hay estudios que concluyen que la crioconservación es una forma de eliminación de embriones, debido a la cifra baja de embriones que sobreviven al descongelarlos y a las tasas de embarazos, que también son menores que aquellas obtenidas con embriones frescos. Véase López-Moratalla, Natalia: "La Discusión Bioética sobre la Reproducción Humana Asistida: Aspectos Biológicos”, 2006, p. 21.

${ }^{30}$ Art. 14.3, Ley 40/2004. La crioconservación de embriones es una alternativa excepcional y de emergencia para salvar la vida del embrión, por lo que no puede acordarse previamente entre la unidad de medicina reproductiva y los pacientes.
} 
tanto, de quedar un embrión sin transferirse a su madre por alguna de estas causas, morirá, entendiéndose como una pérdida del embarazo —o aborto- - por enfermedad incompatible o por muerte de la madre ${ }^{31}$.

\section{4.d) Diagnóstico genético preimplantacional}

Otra práctica que afecta al embrión es el diagnóstico genético preimplantacional, el cual consiste en analizar células de embriones in vitro para detectar anomalías, especialmente de orden cromosómico, que puedan comprometer la viabilidad del embrión o enfermedades genéticas hereditarias, esto, con el objetivo de seleccionar los embriones sanos para transferir.

En España, el diagnóstico genético preimplantacional no sólo se autoriza por la Ley 14/2006 para la detección de enfermedades hereditarias graves no susceptibles de tratamientos curativos postnatales o de otras alteraciones que puedan comprometer la viabilidad del embrión, sino que también se admite con fines terapéuticos para terceras personas (art. 12). Por medio del diagnóstico preimplantacional a favor de terceros se determina la compatibilidad de un embrión con la enfermedad de un hermano/hermana enferma, se transfiere el embrión compatible y se dispone, una vez nacido, de material (cordón umbilical, médula u otro) para realizar un trasplante ${ }^{32}$.

La Ley española 14/2006 de reproducción asistida en la exposición de motivos señala que "El diagnóstico genético preimplantacional abre nuevas vías en la prevención de enfermedades genéticas que en la actualidad carecen de tratamiento y a la posibilidad de seleccionar preembriones para que, en determinados casos y bajo el debido control y autorización administrativos, puedan servir de ayuda para salvar la vida del familiar enfermo”. Este reconocimiento junto con la ausencia de una norma que prohíba fecundar óvulos humanos con fines distintos al de procreación humana permiten la realización de una técnica de reproducción asistida con el propósito ex-

${ }^{31}$ La reglamentación de los embriones crioconservados con anterioridad a la Ley 40/2004 se delega al Ministerio de Salud, en cuanto la crioconservación no estaba prohibida en los centros privados (art. 17.e, Ley 40/2004). Las líneas guías dictadas por este ministerio sobre las indicaciones del procedimiento y técnicas de procreación médicamente asistida se limitan a diferenciar entre los embriones crioconservados con anterioridad a la Ley 40/2004 y aquellos declarados en estado de abandono. Respecto de los primeros dictamina su crioconservación hasta su transferencia a la madre, quien siempre se puede oponer a recibirlos. En cuanto a los segundos, precisa los requisitos de la declaración del estado de abandono y la forma en que deben ser congelados, pero nada dice sobre el futuro de esos embriones abandonados y tampoco habla de la posibilidad de darlos en adopción.

32 Véase Vidal, Francesca, “Diagnóstico Preimplantacional”, 2007, p.193. 
clusivo de seleccionar uno o más embriones para destinarlos a la cura de enfermedades de terceras personas.

La ley italiana de reproducción asistida, por el contrario, impide el diagnóstico genético preimplantacional de embriones al prohibir cualquier experimentación con embriones humanos (Ley 40/2004, art. 13.1). La investigación clínica y experimental no puede tener fines selectivos, sino exclusivamente terapéuticos y de diagnósticos y debe tutelar la salud y el desarrollo del embrión (art. 13.2). Por último, se deben transferir todos los embriones fecundados — con un máximo de tres—, tengan o no alteraciones cromosómicas y sean o no portadores de enfermedades (art. 14.2).

\section{4.e) Reducción embrionaria}

La Ley española 14/2006 de reproducción asistida no autoriza expresamente la reducción embrionaria o aborto selectivo de embriones transferidos. Sin embargo, al no estar prohibida se practica en centros de medicina reproductiva españoles en casos de embarazos múltiples, esto es, con tres o más fetos, a fin de disminuir el número de embarazos simultáneos. La posición médica es que se trata de un aborto y como éste sí está autorizado legalmente, se llevaría a cabo como un aborto selectivo, justificado, por ejemplo, en la salud psíquica de la madre ${ }^{33}$.

Por el contrario, la Ley 40/2004 de reproducción asistida italiana prohíbe la reducción embrionaria. Esta prohibición afecta por lo tanto a los embarazos múltiples que se pueden producir al ser obligación transferir todos los óvulos fecundados —en un máximo de tres_-, y a los embriones enfermos que son transferidos al estar prohibido el diagnóstico genético preimplantacional. Sin embargo, se excluyen de la regla (prohibición de reducción embrionaria) los casos de aborto permitidos por la Ley 194 del 22 de mayo de $1978^{34}$. Esta excepción consiste en permitir la interrupción de un embarazo producto de un tratamiento de asistencia de reproducción cuando

${ }^{33}$ Ley Orgánica 9/1985 del 5 de julio (ley de aborto española). En los “Aspectos Éticos de la Reducción del Número de Embriones”, la Asociación Médica Mundial (resolución adoptada por la 47 ${ }^{\mathrm{a}}$ Asamblea General de la AMM, Indonesia, septiembre de 1995) señala que en el FIV no se deben transferir más de tres embriones y en la IA se debe llevar un control de la estimulación, observando cuidadosamente el tratamiento, inclusive con ultrasonido y hormonas, autorizando en algunos casos la reducción del número de ovocitos, debiéndose recomendar cuando es médica y técnicamente posible. Sin embargo, cuando a pesar de estas precauciones se produce inevitablemente un embarazo con tres o más fetos, la Asociación admite la reducción embrionaria. También cuando el pronóstico para los fetos sea tan desfavorable, que sea necesario para permitir o mejorar la supervivencia de los restantes.

${ }^{34}$ Art. 14.4, Ley 40/2004. 
pone en riesgo la salud física o psíquica de la madre o el feto sufre alguna malformación o anomalía ${ }^{35}$.

Llama la atención que en Italia una ley —la de reproducción asistida - prohíba el diagnóstico genético preimplantacional de embriones y la reducción embrionaria (normas que van en perfecta continuidad con el objeto de la ley de admitir las técnicas de reproducción con pleno respeto de la vida del embrión en sus diversas etapas) y que otra ley - la de interrupción del embarazo o "ley de aborto" - permita eliminar por causas legales tan amplias como la salud psíquica de la madre, el mismo ser que antes de su transferencia es protegido en forma absoluta por la ley de reproducción asistida.

A juicio de algunos autores, esta discontinuidad en el ordenamiento jurídico italiano entre la Ley 40/2004 sobre reproducción asistida y la Ley 194/1978 sobre interrupción voluntaria del embarazo no es tal, porque “desde el punto de vista de las definiciones jurídicas no existe entre la Ley 194/ 1978 y la Ley 40/2004 ni superposición ni discontinuidad: en particular, la primera se refiere a la fase en que el embrión, o feto, se encuentra en el cuerpo materno, mientras que ambas normativas parten [...] del reconocimiento del valor de la maternidad y del derecho de la vida desde su inicio. La ley de procreación asistida establece reglas con las que se desea que el recurso a la fecundación in vitro esté orientado, justamente, en sentido procreativo, de manera que el hecho de que la fecundación se produzca fuera del cuerpo femenino no excluye a priori a ninguno de los embriones generados de la posibilidad de desarrollo. Y la ley sobre el aborto no extiende el ámbito en que una interrupción del embarazo puede estar exenta de sanción más allá de los límites marcados por 'una peculiar y tipificada eximente del estado de necesidad' [...] evitando dar cobertura jurídica a un comportamiento discrecional con respecto al concebido durante la gestación [...] y considerar indiferente, incluso en presencia de los requisitos relevantes a los efectos de la no punibilidad, el resultado abortivo: como demuestra, entre otros, el compromiso (destinado) a 'examinar las posibles soluciones de los problemas propuestos' y a 'suprimir las causas que llevarían [a la mujer] a la interrupción del embarazo’”36.

No obstante las declaraciones formales de las leyes italianas de reproducción asistida y aborto, el conflicto entre ambas radica en que en el

${ }^{35}$ La Corte Constitucional italiana ha señalado que la vida y la salud del concebido no pueden jamás prevalecer sobre los valores de la vida y salud de la madre, al menos hasta que termine la intermediación del concebido con su cuerpo (Sentencias N 27/1975 y $\mathrm{N}^{\circ}$ 37/1997).

${ }^{36}$ Eusebi, Luciano: "Problemas Jurídicos de la Fecundación Humana Extracorpórea: La Normativa Italiana”, 2006, pp. 79 y 80. 
cumplimiento de su objeto protegen bienes jurídicos diferentes que se traducen en la desprotección por parte de uno de aquellos protegidos por la otra. La Ley 40/20004 sobre reproducción asistida italiana tiene como objeto facilitar la reproducción humana cuando no es posible de forma espontánea y la Ley 194/1978 sobre interrupción voluntaria del embarazo busca no sancionar un acto discrecional de concurrir ciertos acontecimientos que afectan a la mujer. En esta búsqueda, la Ley de reproducción asistida protege el derecho del embrión a desarrollarse, mientras que la "ley de aborto" protege el bienestar de la mujer. En esta superposición en la Ley 194/1978 del bienestar de la mujer sobre la vida del feto se desampara al embrión protegido en la ley de reproducción asistida. A su vez, la Ley 40/2004, en tutela del derecho a la vida del embrión, limita la voluntad de la mujer y consagra en su art. 6 la obligación de la madre de recibir los embriones producto de un tratamiento de asistencia de reproducción, y la autoriza a revocar el consentimiento dado para la aplicación de la técnica sólo hasta el momento previo de la fecundación del óvulo. Luego, debe necesariamente recibir a los embriones, aun cuando por una causa sobreviniente se encuentre en estado de necesidad.

De este modo, si bien puede que ambas leyes en sí mismas no tengan contradicciones ya que sus propias normas son coherentes, sí es posible inferir que en el ordenamiento jurídico italiano se presenta un conflicto, en cuanto dos leyes coexistentes en cumplimiento de objetivos específicos valoran de forma diferente la vida del no nacido y la voluntad de la mujer. Este escenario se debe en parte a la ambigua protección constitucional del derecho de la vida en Italia ${ }^{37}$.

\section{4.f) Técnicas terapéuticas}

Las técnicas terapéuticas —esto es, toda intervención en embriones vivos in vitro realizada con el fin de tratar una enfermedad o impedir su transmisión- aparecen tratadas en ambas legislaciones de manera semejante. La ley española señala que "cualquier intervención con fines terapéuticos sobre el embrión vivo in vitro sólo puede tener por finalidad tratar una enfermedad o impedir su transmisión, con garantías razonables y contrastadas” y con probabilidades de mejoría. La ley italiana también las permite con fines exclusivamente terapéuticos y diagnósticos que velen por la tutela de la salud y desarrollo del embrión, cuando no haya metodologías alternativas. A su vez, en ambas leyes se prohíbe la alteración del patrimonio genéti-

${ }^{37}$ Véase nota 14, supra. 
co hereditario del embrión, pero se permite la alteración de los caracteres hereditarios patológicos (enfermedades transmisibles) realizadas con fines de terapia y diagnóstico ${ }^{38}$. Sin embargo, la diferencia radica en que en Italia las técnicas terapéuticas sobre embriones (y también gametos) sólo se pueden realizar respecto de parejas con problemas de esterilidad o infertilidad, quedando excluidas de esta posibilidad las parejas fértiles pero portadoras de enfermedades, en cuanto sólo las primeras se admiten como usuarias de una técnica de reproducción asistida.

\section{4.g) Clonación}

Tanto España como Italia prohíben la clonación con fines reproductivos, que es la "producción de un ser humano genéticamente idéntico a otro, a partir del material genético de una célula de la persona que se va a copiar”39. Específicamente en el artículo 1.3 de la Ley 14/2006 española y en los artículos 12.7 y 13.3 letra c de la Ley 40/2004 italiana.

No obstante la prohibición común de ambas legislaciones, en España no está prohibida la clonación terapéutica de embriones, que es la producción de un organismo humano por medio de la clonación y la obtención de su célula madre con el fin de tratar enfermedades de terceros. La Ley 14/ 2006 de reproducción asistida española sólo sanciona la clonación con fines reproductivos, dejando abierta la puerta a la clonación terapéutica. La Ley 14/2007 sobre investigación biomédica (artículos 33.1 y 2) la autoriza expresamente siempre que se trate de embriones sobrantes de técnicas de reproducción, no creados con ese fin exclusivo: "Se prohíbe la constitución de preembriones y embriones humanos exclusivamente con fines de experimentación. Se permite la utilización de cualquier técnica de obtención de células troncales humanas con fines terapéuticos o de investigación, que no comporte la creación de un preembrión o de un embrión exclusivamente con ese fin, en los términos definidos en esta ley, incluida la activación de ovocitos mediante transferencia nuclear".

La Ley italiana 40/2004, en cambio, prohíbe expresamente la clonación terapéutica ${ }^{40}$.

${ }^{38}$ Art. 13, Ley española 14/2006 de reproducción asistida y art. 13.2 y 13.3 letra b) de la Ley italiana 40/2004 de reproducción asistida.

${ }^{39}$ Diccionario Médico, Clínica Universitaria, Universidad de Navarra, internet, www.cun.es/nc/areadesalud/diccionario, septiembre 2008.

${ }^{40}$ Art. 13.3 letra c, Ley 40/2004: "Están no obstante prohibidas las intervenciones de clonación mediante transferencia de núcleo o de división precoz del embrión o de octogénesis con fines procreativos o de investigación”. 


\section{Reflexiones finales}

Hasta el año 2008 la protección legal del embrión en Chile suscitaba interrogantes por la ausencia de una norma explícita que consagrara su derecho a la vida. El artículo 19.1 de la Constitución de la República, que asegura a todas las personas el derecho a la vida y ordena a la ley —al igual que el artículo 75 del Código Civil— proteger la vida del que está por nacer, no precisa quién es el que “está por nacer” —embrión o feto— ni tampoco si el concebido es persona. Ese año, la duda fue zanjada por el Tribunal Constitucional al señalar en una sentencia que el embrión desde la concepción sí es persona y, por lo mismo, sujeto del derecho de la vida.

En materia de procreación asistida, Chile no tiene una ley específica. Los centros de medicina reproductiva se autorregulan y no hay normas estandarizadas que determinen los actos permitidos y prohibidos, lo que puede llevar a situaciones fácticas contrarias al ordenamiento jurídico, como la existencia de embriones sobrantes sin destino y la eliminación de los mismos. Ante estas realidades se potencia la necesidad de legislar, siendo útil en ello el conocimiento de legislaciones extranjeras como las leyes de reproducción asistida española e italiana.

Teniendo en consideración el ordenamiento jurídico chileno, de los dos casos analizados en este estudio, la Ley 14/2006 de España no es un modelo idóneo para seguir en Chile, porque contempla actos que desfavorecen el desarrollo del embrión, como la investigación o experimentación con embriones viables y el diagnóstico genético preimplantacional tanto para la selección de embriones sanos como para terapias a favor de terceros. A su vez, no limita la cantidad de óvulos a fecundar por ciclo, lo que produce embriones sobrantes — no transferidos-, la crioconservación de los mismos y, finalmente, el desecho de embriones sin destino (aquellos que, transcurrido el tiempo de crioconservación, no son transferidos a una mujer), todo para favorecer el éxito de las técnicas.

Por el contrario, la Ley italiana 40/2004 de reproducción asistida sí es un modelo homologable a nuestra realidad jurídica, pues tiene como objetivo favorecer la procreación humana en parejas con problemas de esterilidad o infertilidad con respeto al derecho de la vida del embrión. Así, las limitaciones a las prácticas se fijan en atención a las garantías de desarrollo o salud del concebido. Para ello evita la existencia de embriones sobrantes limitando a tres el máximo de óvulos a fecundar y exige la transferencia de todos los embriones resultantes del proceso. Prohíbe la crioconservación de embriones, admitiéndola sólo excepcionalmente cuando es imposible la 
transferencia inmediata por razones imprevistas y de fuerza mayor, con el fin de favorecer sus posibilidades de desarrollo.

Con el mismo propósito de velar por el derecho a la vida del embrión, la ley italiana de reproducción asistida prohíbe también la investigación y experimentación con embriones, la clonación terapéutica y el diagnóstico genético preimplantacional.

El análisis comparativo de las leyes española e italiana de reproducción asistida reviste interés más allá del trato dado al embrión, no obstante ser éste un tema determinante en la sugerencia de considerarla en Chile. Dentro de las otras materias analizadas destacan los desaciertos legales, como los vacíos de la primera ley española de reproducción asistida que llevaron a consecuencias indeseadas por el legislador y que motivaron su posterior reforma y luego su derogación, para ser remplazada por la Ley $14 / 2006$.

Asimismo, del estudio se desprende la importancia de la definición de los objetivos de la ley. El señalar como propósito exclusivo la ayuda a parejas que no pueden procrear espontáneamente, o bien precisar fines ajenos a la reproducción humana en caso de infertilidad, como la cura de enfermedades o la reproducción de personas fértiles (portadoras de enfermedades genéticas o mujeres solas), determina también los actos que deberán ser admitidos o prohibidos en la legislación.

Si los legisladores chilenos toman la decisión de regular las prácticas de reproducción asistida, el conocimiento de las leyes y experiencia de otros países entrega luces sobre los errores, contradicciones y problemas en la implementación de las leyes y permite anticipar incoherencias entre distintos cuerpos legales, especialmente de orden constitucional, todo lo cual contribuye a agilizar y facilitar el trabajo legislativo.

\section{REFERENCIAS BIBLIOGRÁFICAS}

\section{Legislaciones, tratados, convenciones, sentencias, ordenanzas y acuerdos}

\section{I.a) España}

Ley Orgánica 9/1985, del 5 de julio, de reforma del artículo 417 bis del Código Penal (despenalización del aborto en determinados supuestos).

Ley 35/1988, de 22 de noviembre, sobre técnicas de reproducción asistida.

Real Decreto 415/1997, de 21 de marzo, por el que se crea la Comisión Nacional de Reproducción Asistida.

Ley 45/2003, del 21 de noviembre, por la que se modifica la Ley 35/1988 de 22 de noviembre, sobre técnicas de reproducción asistida. 
Real Decreto 1720/2004, del 23 de julio, que establece las tipologías fisiopatológicas que permiten la superación de los límites generales establecidos para la fecundación de ovocitos en procesos de reproducción asistida.

Ley 14/2006, del 26 de mayo, sobre técnicas de reproducción humana asistida.

Ley 14/2007, de 3 de julio, de investigación biomédica.

Real Decreto 906/2007 de 6 de julio, por el que se modifica la Comisión Nacional de Reproducción Asistida (para adecuarla a la Ley 14/2006).

\section{I.b) Italia}

Constitución de la República Italiana, de 21 de diciembre de 1947.

Ley 194, de 28 de mayo, 1978, que regula la tutela de la maternidad y la interrupción voluntaria del embargo (Legge 22 maggio 1978, Norme per la tutela sociale della maternitá e sull' interruzione voluntaria della gravidanza.).

Ministerio de Salud de Italia: Circular de 1 de marzo de 1985, Límites y condiciones de legitimidad de los servicios para la inseminación artificial en el ámbito del Servicio Sanitario Nacional. (Ministero Della Sanità circolare 1 marzo 1985, Limiti e condizioni di legittimtà dei servizi per l'inseminazione artificiale nell'ambito del SSN.)

Ministerio de Salud de Italia: Ordenanza de 5 de marzo de 1997, Prohibición de comercialización y publicidad de gametos y embriones humanos. (Ministero Della Sanità, ordinanza 5 marzo 1985, Divieto di commercializzazione e pubblicità di gameti ed embrioni umani.)

Tribunal Constitucional de Italia. Sentencias No 27/1975; N 35/1997; 37/1997.

Ministerio de Salud de Italia: Ordenanza del 25 de julio de 2001, Prohibición de importación y exportación de gametos y embriones humanos. (Ministero Della Sanità, ordinanza 25 luglio 2001, Divieto di importazione e di esportazione di gameti ed embrioni umani.)

Ley 40 de 19 de febrero de 2004, Normas en materia de procreación médicamente asistida. (Legge 19 febbraio 2004 n. 40, Norme in materia di procreazione medicalmente assistita.)

\section{I.c) Otras legislaciones, sentencias, tratados, convenciones y acuerdos internacionales}

Declaración de Helsinki de la Asociación Médica Mundial de 1964.

Tribunal Constitucional Alemán de 1975: Sentencia BverfGE 39,1, 37.

Parlamento Europeo: Resolución sobre fecundación in vitro, 1989.

Convención Americana sobre Derechos Humanos (Pacto de San José de Costa Rica). Ratificado por Chile en 1990.

Red Latinoamericana de Reproducción Asistida (Red): Consenso Latinoamericano en aspectos ético-legales relativos a las técnicas de reproducción asistida, 1995.

Convenio Europeo de Derechos Humanos y Biomedicina (Oviedo), del 4 de abril de 1997. Ratificado por España el 23 de julio de 1999.

Tribunal Constitucional, Chile: Sentencia del Tribunal Constitucional de fecha 18 de abril de 2008, Rol 740-07-CDS, IV. "Protección constitucional de la vida en Chile".

Ley 20.120 sobre investigación científica en el ser humano, su genoma y prohíbe la clonación. 


\section{Trabajos y libros citados}

Asociación Médica Mundial: “Aspectos Éticos de la Reducción del Número de Embriones” (adoptada por la 47 Asamblea General de la AMM, Indonesia, septiembre de 1995).

Bascuñán Rodríguez, Antonio: "La Píldora del Día Después ante la Jurisprudencia. En Estudios Públicos, 95 (2004).

Casini, Carlos, Marina Casini y María Luisa Di Pietro: La legge 19 de febbraio 2004, $N^{\circ} 40$, Norme in materia di procreazione medicalmente assistita, comentario. Torino: giappichelli, 2004.

El País, 5 de julio de 2003, p. 30 España. Crónica sobre número de embriones congelados en España.

Eusebi, Luciano: "Problemas Jurídicos de la Fecundación Humana Extracorpórea: La Normativa Italiana”. En Cuadernos de Derecho Judicial XI. Legislación sobre Reproducción Asistida: Novedades. Madrid, 2006.

Ferrer V., María Pilar: “Gestación por Sustitución: Comentario Jurídico”. En Francisco Lledó Y., M. Carmen Ochoa y Óscar Monje B (eds.), Comentarios CientíficoJurídicos a la Ley sobre Técnicas de Reproducción Humana Asistida (Ley 14/ 2006, de 26 de mayo). Madrid: Editorial Dykinson, 2007.

López-Moratalla, Natalia: "La Discusión Bioética sobre la Reproducción Humana Asistida: Aspectos Biológicos”. En Cuadernos de Derecho Judicial XI. Legislación sobre Reproducción Asistida: Novedades. Madrid, 2006.

Ugarte Godoy, José Joaquín: "Momento en que el Embrión Es Persona Humana”. En Estudios Públicos, 96 (2004).

Universidad de Navarra, Clínica Universitaria: Diccionario Médico, internet, www.cun. es/nc/areadesalud/diccionario, septiembre 2008.

Vidal, Francesca: "Diagnóstico Preimplantacional: Comentario Científico". En Francisco Lledó Y., M. Carmen Ochoa y Óscar Monje B. (eds.), Comentarios Científico-Jurídicos a la Ley sobre Técnicas de Reproducción Humana Asistida (Ley 14/2006, de 26 de mayo). Madrid: Editorial Dykinson, 2007. 